\title{
Self-organized classification of boundary layer meteorology and associated characteristics of air quality in Beijing
}

\author{
Zhiheng Liao ${ }^{1}$, Jiaren Sun ${ }^{1,2}$, Jialin Yao ${ }^{3}$, Li Liu $^{1}$, Haowen $\mathrm{Li}^{1}$, Jian Liu ${ }^{1}$, Jielan Xie ${ }^{1}$, Dui Wu ${ }^{4,5}$, and Shaojia Fan ${ }^{1}$ \\ ${ }^{1}$ School of Atmospheric Sciences, Sun Yat-sen University, Guangzhou, Guangdong, China \\ ${ }^{2}$ South China Institute of Environmental Sciences, Ministry of Environmental Protection of the People's Republic of China, \\ Guangzhou, Guangdong, China \\ ${ }^{3}$ Weather Modification Office of Shanxi Province, Taiyuan, Shanxi, China \\ ${ }^{4}$ Institute of Mass Spectrometer and Atmospheric Environment, Jinan University, Guangzhou, Guangdong, China \\ ${ }^{5}$ Guangdong Engineering Research Centre for Online Atmospheric Pollution Source Appointment Mass Spectrometry \\ System, Jinan University, Guangzhou, Guangdong, China
}

Correspondence: Shaojia Fan (eesfsj@mail.sysu.edu.cn) and Jiaren Sun (sunjiaren@scies.org)

Received: 7 November 2017 - Discussion started: 13 December 2017

Revised: 17 April 2018 - Accepted: 21 April 2018 - Published: 15 May 2018

\begin{abstract}
Self-organizing maps (SOMs; a feature-extracting technique based on an unsupervised machine learning algorithm) are used to classify atmospheric boundary layer (ABL) meteorology over Beijing through detecting topological relationships among the 5-year (2013-2017) radiosondebased virtual potential temperature profiles. The classified ABL types are then examined in relation to near-surface pollutant concentrations to understand the modulation effects of the changing ABL meteorology on Beijing's air quality. Nine ABL types (i.e., SOM nodes) are obtained through the SOM classification technique, and each is characterized by distinct dynamic and thermodynamic conditions. In general, the selforganized ABL types are able to distinguish between high and low loadings of near-surface pollutants. The average concentrations of $\mathrm{PM}_{2.5}, \mathrm{NO}_{2}$ and $\mathrm{CO}$ dramatically increased from the near neutral (i.e., Node 1) to strong stable conditions (i.e., Node 9) during all seasons except for summer. Since extremely strong stability can isolate the near-surface observations from the influence of elevated $\mathrm{SO}_{2}$ pollution layers, the highest average $\mathrm{SO}_{2}$ concentrations are typically observed in Node 3 (a layer with strong stability in the upper ABL) rather than Node 9 . In contrast, near-surface $\mathrm{O}_{3}$ shows an opposite dependence on atmospheric stability, with the lowest average concentration in Node 9. Analysis of three typical pollution months (i.e., January 2013, December 2015 and December 2016) suggests that the ABL types are the primary drivers of day-to-day variations in Beijing's air quality. Assuming a
\end{abstract}

fixed relationship between $\mathrm{ABL}$ type and $\mathrm{PM}_{2.5}$ loading for different years, the relative (absolute) contributions of the ABL anomaly to elevated $\mathrm{PM}_{2.5}$ levels are estimated to be $58.3 \%\left(44.4 \mu \mathrm{g} \mathrm{m}^{-3}\right)$ in January $2013,46.4 \%\left(22.2 \mu \mathrm{g} \mathrm{m}^{-3}\right)$ in December 2015 and $73.3 \%\left(34.6 \mu \mathrm{g} \mathrm{m}^{-3}\right)$ in December 2016.

\section{Introduction}

The atmospheric boundary layer $(\mathrm{ABL})$ is the section of the atmosphere that responds directly to the flows of mass, energy and momentum from the earth's surface (Stull, 1988). Since most air pollutants are emitted or chemically produced within this layer, its evolution plays an important role in the transport, dispersion and deposition of air pollutants (Chen et al., 2012; Fan et al., 2008; Whiteman et al., 2014; Platis et al., 2016; Wolf et al., 2014; Wu et al., 2013). The ABL structure is determined by complex interactions between atmosphere static stability and those mechanical processes (such as wind shear from synoptic or terrain-induced flows) (Stull, 1988). These processes can operate at a variety of different heights and temporal scales, and their dominance may vary considerably with height and time at any given location (Salmond and McKendry, 2005). This makes it very difficult to observe and predict the transport and diffusion of air pollutants within the 
ABL (Chambers et al., 2015b, a), particularly in regions of complex terrain such as Beijing.

Beijing, the capital of China, is geographically located at the northwestern border of the North China Plain. This city is surrounded by the Yan Mountains to the north and the Taihang Mountains to the west, with the Bohai Sea $160 \mathrm{~km}$ to the southeast (Fig. 1). Under favorable weather conditions (e.g., stagnant weather), terrain-related circulations can be well developed over Beijing and its surroundings, leading to a complex ABL structure, which is thought to substantially affect Beijing's air quality (Hu et al., 2014; Miao et al., 2017; Ye et al., 2016; Gao et al., 2016; Xu et al., 2016). With high emissions of air pollutants from anthropogenic sources, Beijing is suffering serious air pollution problems and the pollution can be even more severe when southwesterly and southeasterly winds prevail within the ABL (Chen et al., 2008; Ye et al., 2016; Zhang et al., 2014, 2012).

Several studies investigated the interactions between ABL meteorology and air quality in Beijing using tower-based observations (Sun et al., 2013, 2015; Guinot et al., 2006; Guo et al., 2014). However, the results are not ideal because the tower-based observations have a low observational height $(325 \mathrm{~m})$. In addition, numerous intensive ABL measures were conducted using other approaches such as mooring boats, airplane and ground-based remote sensing (Tang et al., 2015; Zhu et al., 2016; Zhang et al., 2009; Hua et al., 2016). Since these approaches are complex, expensive and labor-intensive, they are often restricted to the duration of specific research campaigns and hence their results may be considered to be unrepresentative. Overall, the existing knowledge of linkages between ABL meteorology and air quality in Beijing is drawn largely from either low observational height or short observational duration; therefore, the common patterns of the influence of the changing ABL structures on Beijing's air quality remains unclear and need to be further studied (Quan et al., 2013; Miao et al., 2017; Guo et al., 2014).

Meanwhile, routine radiosondes are not being fully utilized to investigate urban pollution issues. The advantage of using radiosondes over other approaches seems to be their length, which usually spans several decades. For a long time, it was challenging to reduce the wealth of radiosonde data to characterize the ABL structure, and therefore the use of routine radiosondes was very limited in case studies ( $\mathrm{Ji}$ et al., 2012; Zhao et al., 2013; Gao et al., 2016). Recently, self-organizing maps (SOMs; a feature-extracting technique based on an unsupervised machine learning algorithm) (Kohonen, 2001) were introduced to investigate the ABL thermodynamic structure, indicating the capabilities of SOMs in feature extraction from a large dataset of the ABL measurements (Katurji et al., 2015). In fact, the application of the SOM has increased in atmospheric and environmental sciences during the past several years (Jensen et al., 2012; Jiang et al., 2017; Gibson et al., 2016; Pearce et al., 2014; Stauffer et al., 2016), including a radiosonde-based applica- tion in South Africa (Dyson, 2015). However, there has been no SOM application in air-pollution-related ABL structure research thus far. It is expected that such a new analytical approach can tap the potential of routine radiosondes to reveal the ABL mechanism of air pollution in Beijing.

This study investigates the influence of ABL meteorology on Beijing's air quality based on the SOM application to 5 years (2013-2017) of routine meteorological radiosondes. First, we use the SOM technique to classify the state of ABL through detecting topological relationships among the radiosonde-based virtual potential temperature profiles (see Sect. 3.1). Then, we provide a visual insight into nearsurface pollutant variations under various ABL types and discuss the potential physical mechanisms behind their relationships (see Sect. 3.2-3.3). It is expected that such an association between air quality and ABL type could provide local policymakers with useful information for improving the predictions of urban air quality.

\section{Materials and methods}

\subsection{Data preparation and preprocessing}

The recent 5-year (2013-2017) radiosonde data observed at the Beijing Observatory $\left(39.81^{\circ} \mathrm{N}, 116.48^{\circ} \mathrm{E}\right.$; WMO station number 54511) were collected from the University of Wyoming (http://weather.uwyo.edu/, last access: 25 March 2018). The radiosondes were launched twice a day (08:00 and 20:00 LT, corresponding to the morning and evening, respectively) and provided atmospheric sounding data (profiles of temperature, relative humidity, wind speed, etc.) at the mandatory pressure levels (e.g., surface, 1000, $925,850,700 \mathrm{hPa}$ ) and additional significant levels. In addition, the hourly near-surface meteorological parameters (including temperature, wind speed and relative humidity, etc.) in 2013-2016 were collected from the Beijing Meteorological Bureau.

We chose $2000 \mathrm{~m}$ above ground level as the upper limit of the ABL based on a number studies investigating the ABL height over Beijing or North China (Tang et al., 2016; Guo et al., 2016; Miao et al., 2017). This height exceeded the top of the $\mathrm{ABL}$ in most cases, and therefore, most ABL processes influencing the near-surface air quality were included in the analysis herein. In our study period, the average number of data points in radiosonde profiles was 3.7 below $500 \mathrm{~m}$ and 10.1 below $2000 \mathrm{~m}$. Despite the coarse resolution, there were enough profile shapes for the SOM technique to classify the state of ABL. A previous radiosonde-based study indicated that surface temperature inversions occur frequently in eastern China (Li et al., 2012), suggesting that all of the radiosondes that measure twice daily mainly represent the nocturnal stable ABL. To record a whole night, the daily ABL profiles were composited from the radiosondes at 20:00 and 08:00 of the next day. 
The mass concentrations of atmospheric pollutants (including $\mathrm{PM}_{2.5}, \mathrm{O}_{3}, \mathrm{NO}_{2}, \mathrm{SO}_{2}$ and $\mathrm{CO}$ ) over Beijing during the period from 2013 to 2017 are obtained from the Ministry of Environmental Protection of the People's Republic of China (http://datacenter.mep.gov.cn/, last access: 31 December 2017). In addition, hourly $\mathrm{PM}_{2.5}$ data measured at the Beijing US Embassy (http://www.stateair.net/, last access: 1 April 2018) are also used in this study. The $\mathrm{PM}_{2.5}$ values in the two datasets show a good consistence, with a mean correlation coefficient of 0.94 . The mean hourly standard error of $\mathrm{PM}_{2.5}$ across sites changes little from 12.6 to 12.9 after the inclusion of the US Embassy data. Hourly concentrations are calculated for the Beijing urban area by averaging concentrations from nine urban sites (including Dongsi, Guanyuan, Tiantan, Wanshouxigong, Aotizhongxin, Nongzhanguan, Gucheng, Haidianwanliu and US Embassy). The daily pollutant concentration is then performed afternoon to afternoon (15:00-15:00), in order to include one whole night in each $24 \mathrm{~h}$ period.

\subsection{Self-organizing map technique}

The SOM is thought to be an ideal tool for feature extraction because the input data are treated as a continuum without relying on correlation, cluster or eigenfunction analysis (Liu et al., 2006). Since Kohonen (1982) first proposed the SOM, it has been widely used for data downscaling and visualization in various disciplines (Jensen et al., 2012; Katurji et al., 2015; Dyson, 2015; Stauffer et al., 2016; Pearce et al., 2014; Jiang et al., 2017). In this study, the SOM is introduced to classify the ABL types through detecting topological relationships among the 5-year (2013-2017) radiosonde-based virtual potential temperature profiles. Since the SOM is sensitive to the virtual potential temperature value, the deviation profiles, which are determined by subtracting the mean virtual potential temperature of each profile from each level, are used as the SOM input.

The training of the SOM is an unsupervised, iterative procedure, and the result is a matrix of nodes (i.e., types) that represent the input data. The following provides a simple introduction about the SOM algorithm, and the details can be found in Kohonen (2001). To learn from the input data, every SOM node has a parametric reference vector with which it is associated, and these reference vectors are randomly generated. After initialization of the reference vectors, a stochastic input vector is compared to every reference vector, and the closest match, named the best-matching unit, is determined by the smallest Euclidean distance. Each reference vector is then updated so that the best-matching unit and its neighbors become more like the input vector. Whether or not a reference vector learns from the input vector is determined by the neighborhood function. Only reference vectors that are topologically close enough to the best-matching unit will be updated according to the SOM learning algorithm.
The first step of SOM training is to determine a matrix size of nodes for initializing the reference vectors. This step is performed subjectively and depends on the degree of generation required (Lennard and Hegerl, 2015). We test several SOM matrixes, and finally select a $3 \times 3$ matrix, because it captured unique profiles without the profiles being too general as with a smaller matrix, or being too similar as with a larger matrix. In addition, the batch mode is chosen to execute the SOM algorithm, because it is much more computationally efficient compared to the sequence mode. The other user-defined settings in the SOM software are set at the default, such as the hexagon topology or the Gaussian neighborhood function. The SOM code used in this study is sourced from the MATLAB SOM Toolbox, which is freely available from http://www.cis.hut.fi/projects/ somtoolbox/ (last access date: 1 April 2018).

\subsection{Measuring the discriminative power of SOM technique for pollution assessment}

The Kruskal-Wallis one-way analysis of variance is used as a nonparametric method to test the difference of pollutant concentrations among the various ABL types. A $1 \%$ significance level is used and hereafter denoted as KW in Sect. 3.2. Furthermore, the coefficients of variation (CVs) of pollutant means across the various ABL types are also used to examine the discriminative power of the SOM technique for pollution assessment.

\section{Results and discussion}

\subsection{Self-organized boundary layer meteorology}

We construct a $3 \times 3$ SOM matrix for daily virtual potential temperature deviation profiles, and the self-organized output shown in Fig. 1 represents nine ABL types (i.e., SOM nodes). On the SOM plane, the most notable feature is adjacency of like types (e.g., Nodes 1 and 2) and the separation of contrasting types (e.g., Nodes 1 and 9). Such ordering is a feature of the SOM algorithm (i.e., "self-organized"), which allows us to distinguish the unique characteristics of nodes through the variation of specific features across the SOM plane. According to the ordering feature, the SOM nodes in the four corners (i.e., Nodes 1, 3, 7 and 9) can be thought of as the typical types and the others can be considered as transitional types. The four typical ABL types have a relatively higher occurrence frequency $(>10 \%)$, with the highest frequency associated to Node 1 (23\%). Furthermore, the seasonal statistical results (Fig. 2) reveal that these self-organized ABL types exhibit a strong seasonality. For example, Node 3 occurs more frequently in winter and autumn, while Node 1 has a relatively higher occurrence in spring and summer.

Figure 3 displays the average profiles of wind speed, relative humidity and virtual potential temperature gradient according to the ABL types. Clearly, each of the self-organized 

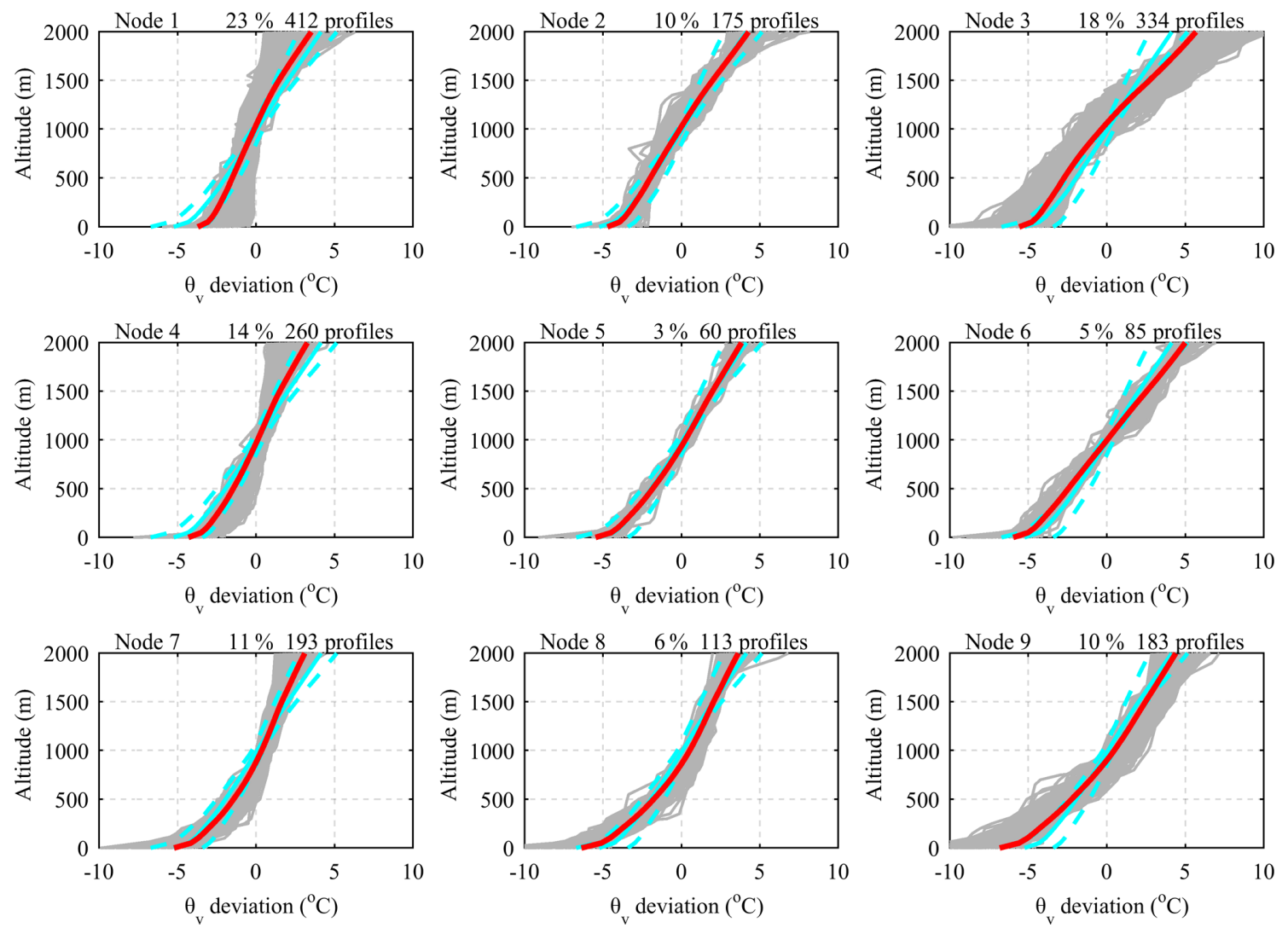

Figure 1. The $3 \times 3$ SOM output for radiosonde-based virtual potential temperature $\left(\theta_{\mathrm{V}}\right)$ deviation profiles observed at the Beijing Observatory. SOM nodes are shown in red, with the corresponding individual profiles in grey. For reference, the overall average $\theta_{\mathrm{v}}$ deviation profile and 25 and 75 th percentile profiles are shown in cyan. The top right of each panel shows the occurrence cases and frequency of each SOM node.

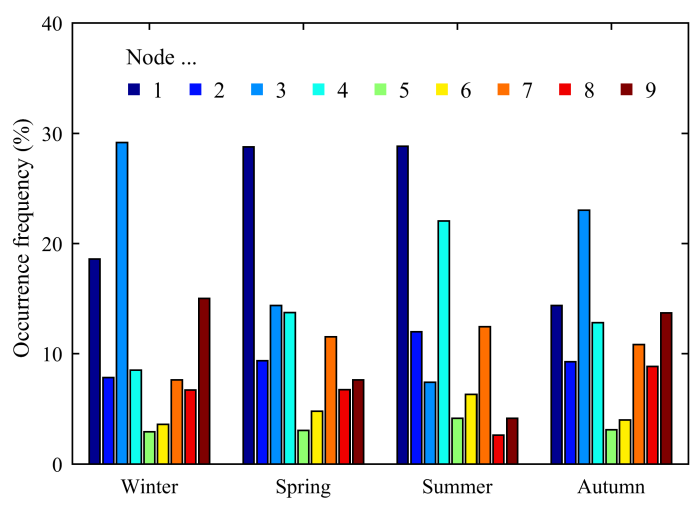

Figure 2. Relative frequency of individual ABL types (i.e., SOM nodes) in all four seasons: winter (DJF), spring (MAM), summer (JJA) and autumn (SON).

types features distinct dynamic and thermodynamic conditions within the ABL, suggesting the SOM technique is feasible to classify the boundary layer meteorology. Since the classification is based on the twice-daily radiosondes, the resulting $\mathrm{ABL}$ types are dominated by near neutral to strong stable conditions, and none of the types fall within the unstable category (i.e., $\Delta \theta_{\mathrm{v}} / \Delta z<0$ ). While Node 3 features the strong static stability in the upper ABL (the large $\Delta \theta_{\mathrm{v}} / \Delta z$ values), Node 1 represents a near neutral ABL condition, with the lowest $\Delta \theta_{\mathrm{v}} / \Delta z$ values and the highest wind shears in the lower ABL. In contrast, Node 7 corresponds to a moderate static stability in the lower ABL, and Node 9 relates to a strong static stability. Particularly, the virtual potential temperature gradient in Node 9 remains at a high level $\left(>0.7^{\circ} \mathrm{C} / 100 \mathrm{~m}\right)$ from the surface to approximately $800 \mathrm{~m}$, indicating that a strong and deep surface temperature inversion developed in this type. In addition, due to the strong surface inversion, vertical mixing is suppressed, resulting in a strong decreasing gradient in humidity profiles. Overall, the SOM classification scheme reveals a significant coupling between dynamic and thermal effects in the ABL, which is expected to considerably impact the near-surface air quality.

To detect the boundary layer development after sunrise, the daytime boundary layer height (BLH) is estimated using the parcel method (Holzworth, 1964, 1967), i.e., intersecting each day's 08:00 radiosonde potential temperature $(\theta)$ profile at Beijing Observatory with each hour's (from 09:00 

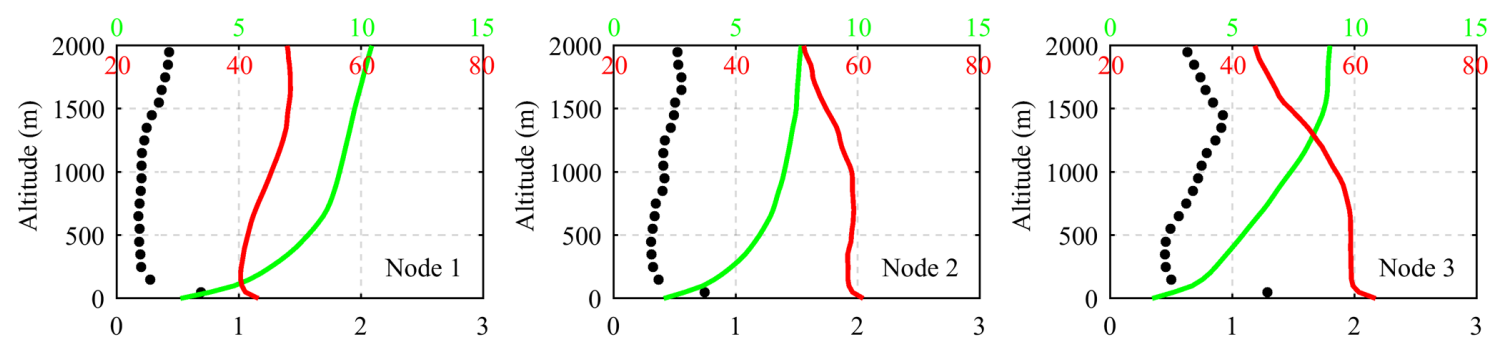

$\Delta \theta_{\mathrm{v}} / \Delta \mathrm{z}\left({ }^{\circ} \mathrm{C} / 100 \mathrm{~m}\right), \mathrm{WS}\left(\mathrm{m} \mathrm{s}^{-1}\right), \mathrm{RH}(\%)$

$\Delta \theta_{\mathrm{v}} / \Delta \mathrm{z}\left({ }^{\circ} \mathrm{C} / 100 \mathrm{~m}\right), \mathrm{WS}\left(\mathrm{m} \mathrm{s}^{-1}\right), \mathrm{RH}(\%)$

$\Delta \theta_{\mathrm{v}} / \Delta \mathrm{z}\left({ }^{\mathrm{o}} \mathrm{C} / 100 \mathrm{~m}\right), \mathrm{WS}\left(\mathrm{m} \mathrm{s}^{-1}\right), \mathrm{RH}(\%)$
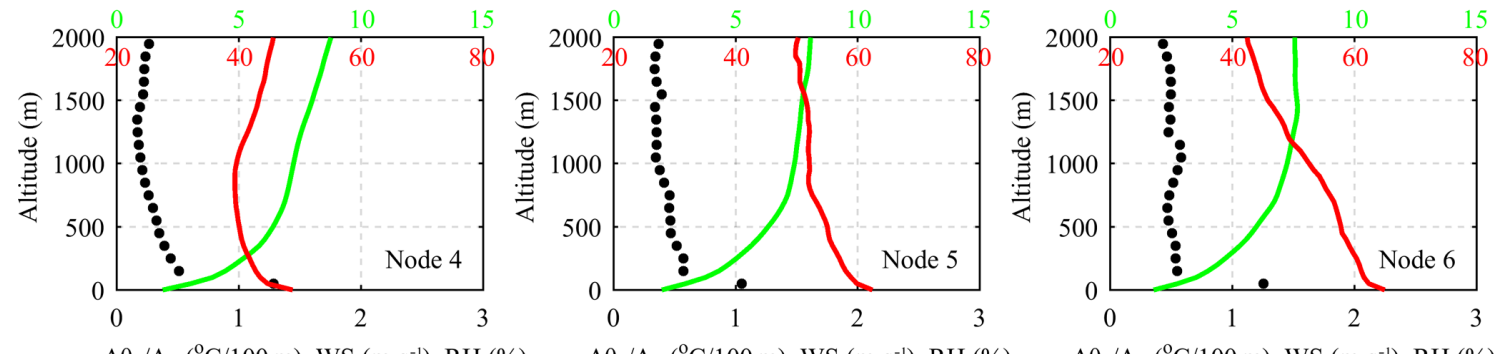

$\Delta \theta_{\mathrm{v}} / \Delta \mathrm{z}\left({ }^{\circ} \mathrm{C} / 100 \mathrm{~m}\right), \mathrm{WS}\left(\mathrm{m} \mathrm{s}^{-1}\right), \mathrm{RH}(\%)$

$\Delta \theta_{\mathrm{v}} / \Delta \mathrm{z}\left({ }^{\circ} \mathrm{C} / 100 \mathrm{~m}\right), \mathrm{WS}\left(\mathrm{m} \mathrm{s}^{-1}\right), \mathrm{RH}(\%)$

$\Delta \theta_{\mathrm{v}} / \Delta \mathrm{z}\left({ }^{\mathrm{o}} \mathrm{C} / 100 \mathrm{~m}\right), \mathrm{WS}\left(\mathrm{m} \mathrm{s}^{-1}\right), \mathrm{RH}(\%)$
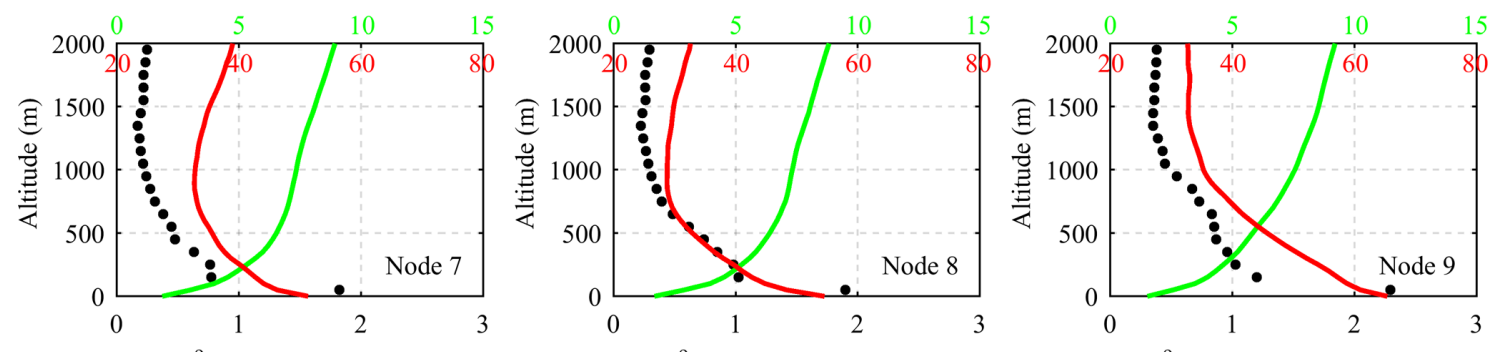

$\Delta \theta_{\mathrm{v}} / \Delta \mathrm{z}\left({ }^{\circ} \mathrm{C} / 100 \mathrm{~m}\right), \mathrm{WS}\left(\mathrm{m} \mathrm{s}^{-1}\right), \mathrm{RH}(\%)$

$\Delta \theta / \Delta \mathrm{z}\left({ }^{\circ} \mathrm{C} / 100 \mathrm{~m}\right), \mathrm{WS}\left(\mathrm{m} \mathrm{s}^{-1}\right), \mathrm{RH}(\%)$

$\Delta \theta / \Delta \mathrm{z}\left({ }^{\circ} \mathrm{C} / 100 \mathrm{~m}\right), \mathrm{WS}\left(\mathrm{m} \mathrm{s}^{-1}\right), \mathrm{RH}(\%)$

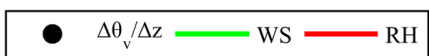

Figure 3. Profiles of average wind speed (WS), relative humidity (RH) and virtual potential temperature gradient $\left(\Delta \theta_{\mathrm{v}} / \Delta z\right)$ corresponding to individual ABL types (i.e., SOM nodes) at the Beijing Observatory. The black, green and red labels of the horizontal axis correspond to $\Delta \theta_{\mathrm{v}} / \Delta z$, WS and $\mathrm{RH}$, respectively.

to $15: 00)$ surface $\theta$ values, which are calculated from surface air temperature observations. As shown in Fig. 4, the BLH on the days following a strong stable night (i.e., Node 1) is relatively flat, reflecting an inadequate development of the daytime boundary layer. Similarly, Node 3 is also followed by a flat daytime BLH variation. The maximum BLHs in these two types are lower than $900 \mathrm{~m}$, indicating a limited space for vertical mixing in the day. In contrast, the afternoon BLH in Node 7 can reach up to $1100 \mathrm{~m}$; this mixing depth is conducive to the dilution of the pollutants accumulated in the previous night. In Node 1, the convective boundary layer develops well, and its maximum height on average exceeds $1500 \mathrm{~m}$, far higher than the values in other types.

\subsection{Implementing the SOM-based ABL classification scheme for urban air quality assessment}

In the previous section, it was seen that the SOM classification scheme is an effective tool for delineation between various dynamic and thermodynamic structures within the ABL.

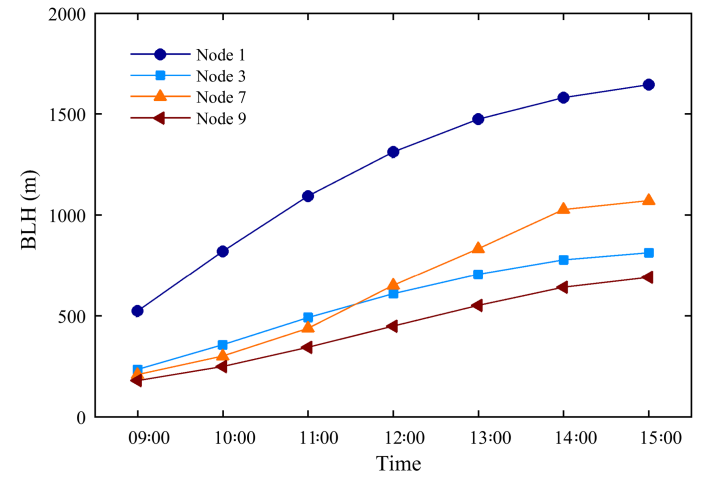

Figure 4. Daytime boundary layer height $(\mathrm{BLH})$ estimated for the four typical ABL types (i.e., Nodes 1, 3, 7 and 9).

As a further evaluation, we implement the new classification scheme to quantify changes in various urban pollutant concentrations as a function of ABL types. Since the pollutant 
emissions have a strong seasonality over Beijing and its surroundings, the analyses are performed for winter (December to February), spring (March to May), summer (June to August) and autumn (September to November), respectively. Figure 5 shows the statistical distributions of daily pollutant concentrations according to the nine ABL types, along with the results of the Kruskal-Wallis test and the coefficients of variation of pollutant means across the various types. Figure 6 displays the type-average pollutant diurnal patterns composited for the four typical ABL types (i.e., Nodes 1, 3, 7 and 9).

The Kruskal-Wallis test demonstrates that the selforganized ABL types are able to distinguish between high and low loadings of air pollutants, with $\mathrm{KW}<1 \%$ in all seasons (except for summertime $\mathrm{SO}_{2}$ with a $\mathrm{KW}$ value of $1.5 \%)$. Furthermore, it is found that the SOM technique has a stronger discriminative power for $\mathrm{SO}_{2}, \mathrm{PM}_{2.5}$ and $\mathrm{CO}$ assessments, which is supported by relatively higher $\mathrm{CV}$ values $(\mathrm{CV}>0.30)$. According to the seasonal $\mathrm{CV}$ values, this discriminative power shows the following seasonal ordering: winter $>$ autumn $>$ spring $>$ summer. Particularly, the wintertime $\mathrm{CV}$ value in $\mathrm{PM}_{2.5}$ assessment reaches the maximum (0.56), indicating an extremely strong dependence of $\mathrm{PM}_{2.5}$ air quality on the changing ABL meteorology in winter. In summer, the stable nocturnal ABL develops later due to the longer day (Li et al., 2012), and hence avoids the larger daytime pollutant emissions, particularly the traffic peak emissions. In the absence of larger sources, the nocturnal stable layers exert a limited influence on near-surface air quality; therefore, the classified ABL types have relatively weakened discriminative power for summertime pollution assessments. In addition, wet deposition (more precipitation in summer) plays an important role in modulating summertime air quality, and to some degree disrupts the linkages between the ABL type and air quality.

In the case of $\mathrm{PM}_{2.5}, \mathrm{NO}_{2}$ and $\mathrm{CO}$, the most stable atmospheric conditions (i.e., Node 9) are associated with dramatically increased near-surface pollutant concentrations in all seasons except summer. The wintertime average concentrations of $\mathrm{PM}_{2.5}, \mathrm{NO}_{2}$ and $\mathrm{CO}$ in Node 9 reach up to 197.2, 100.2 and $3.6 \mu \mathrm{g} \mathrm{m}^{-3}$, respectively. These values are 3-8 times higher than that in Node 1 (i.e., near neutral condition), with the highest increasing amplitude (a factor of 7.3) related to $\mathrm{PM}_{2.5}$. As mentioned, Node 9 corresponds to the strongest nighttime stability in the lower ABL and the lowest daytime BLH. All of these ABL characteristics are extremely conducive to the accumulation of air pollutants emitted near the ground. For Node 3, the concentrations of $\mathrm{PM}_{2.5}, \mathrm{NO}_{2}$ and $\mathrm{CO}$ are the second-highest compared to those of the other types. This ABL type features the strongest stability in the upper $A B L$, suggesting that processes operating at the different heights throughout the ABL may have a significant impact on near-surface pollutant concentrations.

The diurnal cycles of $\mathrm{PM}_{2.5}, \mathrm{NO}_{2}$ and $\mathrm{CO}$ are extremely pronounced under the strong stable conditions, although they are very reduced on the days with near neutral night. On average, the wintertime diurnal range of $\mathrm{PM}_{2.5}$ increases from $18.2 \mu \mathrm{g} \mathrm{m}^{-3}$ in Node 1 to $95.4 \mu \mathrm{g} \mathrm{m}^{-3}$ in Node 9. The corresponding diurnal range increase for $\mathrm{NO}_{2}$ is 18.9 to $33.6 \mu \mathrm{g} \mathrm{m}^{-3}$, and for CO 0.2 to $1.7 \mu \mathrm{g} \mathrm{m}^{-3}$. In Node 1 , the diurnal variations are characterized by a weak two-peak pattern, following the traffic rush hours, suggesting that traffic is the primary driver of these pollutants' diurnal cycles in Beijing (Liu et al., 2012). However, the diurnal effects of traffic emissions are significantly amplified by the stable ABL dynamics. It is clear that the more stable the conditions near the ground, the higher the peak concentrations that are observed. In winter, the stable ABL conditions exert a more important influence on the evening traffic emissions, resulting in a broad evening peak. In contrast, the morning peak signature is much lower since the morning emission is counteracted by the destabilization of the ABL. However, as human activities begin earlier during the warm season, maximum concentrations in spring and summer are typically observed during the morning rush hours.

However, increasing atmospheric stability has the opposite effect on near-surface $\mathrm{O}_{3}$ concentrations. Since aerosols can absorb and reflect solar radiation and thereby inhibit the photochemical production of $\mathrm{O}_{3}$ (Gao et al., 2016; Kaufman et al., 2002), the lowest average $\mathrm{O}_{3}$ concentration is observed in Node 9. In addition, considering that ozone is mainly produced in the upper ABL, near-surface $\mathrm{O}_{3}$ should be strongly modulated by downward mixing processes (Tang et al., 2017b, a). In light of this, the varying daytime $\mathrm{O}_{3}$ peaks across the ABL types can be partly attributed to the various magnitudes of vertical mixing. This is supported by the daytime BLH. As is shown in Fig. 4, the daytime BLH is highest in Node 1, followed by Node 7 and Node 3, and it is the lowest in Node 9. Such ordering is generally consistent with the daytime $\mathrm{O}_{3}$ peaks in these types. Due to the persistent downward mixing caused by strong wind shears, the near-surface $\mathrm{O}_{3}$ remains a relatively high nocturnal concentration (e.g. about $45 \mu \mathrm{g} \mathrm{m}^{-3}$ in winter) in Node 1 . In contrast, the stable nocturnal conditions (e.g., Nodes 9, 7 and 3) are commonly associated with low $\mathrm{O}_{3}$ concentration (e.g. about $16 \mu \mathrm{g} \mathrm{m}^{-3}$ in winter) due to the lack of vertical mixing, as well as the strong chemical titration by $\mathrm{NO}$ emitted from vehicles.

The highest average $\mathrm{SO}_{2}$ concentrations are typically observed in Node 3, but occasionally in Node 9. Over the North China Plain, high stacks emit a significantly larger amount of $\mathrm{SO}_{2}$ compared to small stacks (Zhao et al., 2012). The frequent surface temperature inversions, together with the large $\mathrm{SO}_{2}$ emissions from higher stacks, favor the formation of elevated $\mathrm{SO}_{2}$ pollution layers over Beijing (Chen et al., 2009). If sufficiently strong, the surface temperature inversion can even isolate near-surface observations from the influence of elevated pollution layers (Salmond and McKendry, 2005). This explains the commonly lower near-surface $\mathrm{SO}_{2}$ concentration in Node 9 than that in Node 3. However, after a stable night, the burst of turbulent activity in the morning coincides 

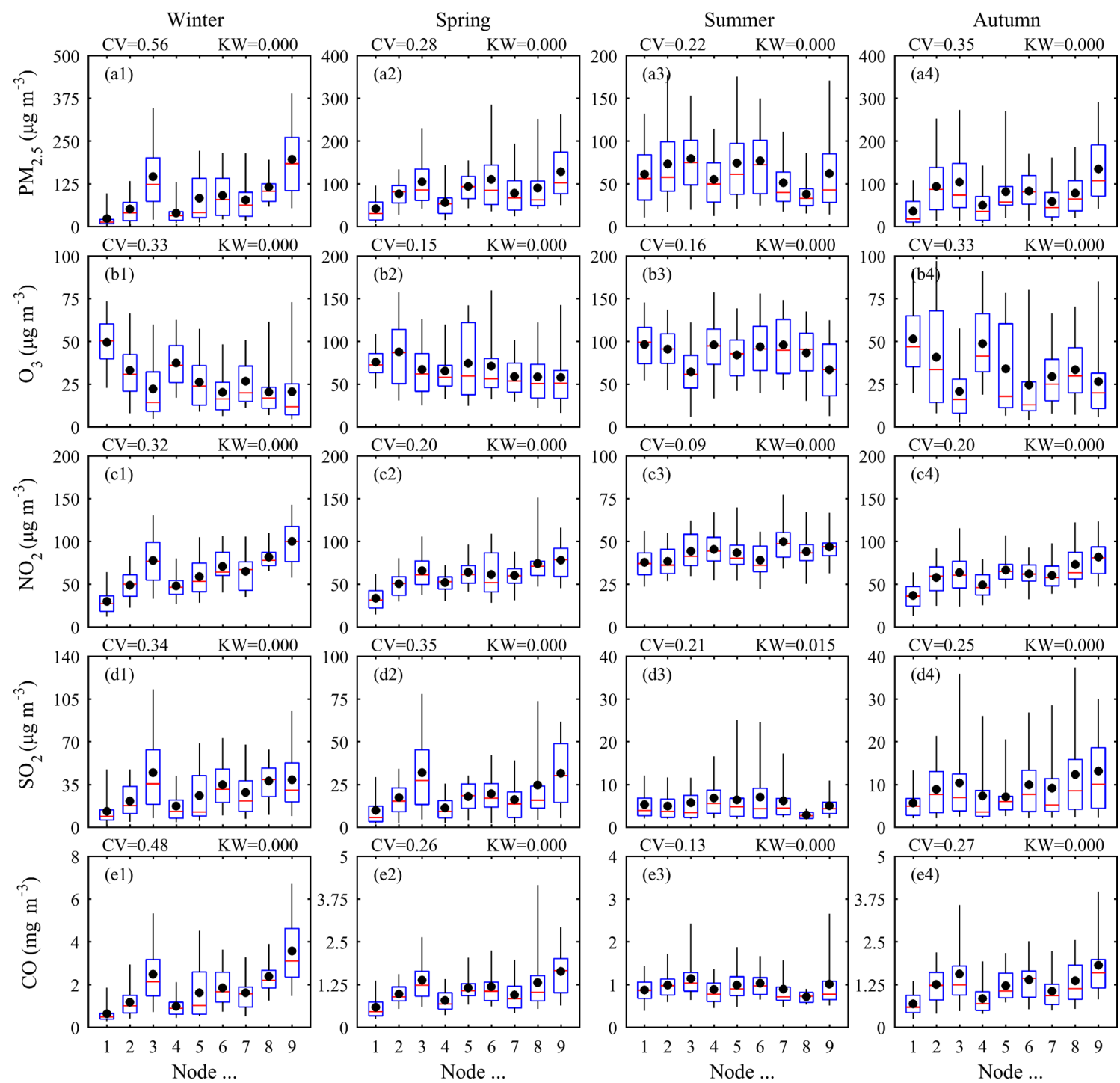

Figure 5. Daily concentrations of (a) $\mathrm{PM}_{2.5}$, (b) $\mathrm{O}_{3}$, (c) $\mathrm{NO}_{2}$, (d) $\mathrm{SO}_{2}$ and (e) CO in Beijing for all nine ABL types separately in (1) winter, (2) spring, (3) summer and (4) autumn. The solid dots denote the mean. The box and whisker plot presents the median, the first and third quartiles and the 5 and 95th percentiles, respectively. The numbers above the plots denote the results of the Kruskal-Wallis test (KW) and the coefficients of variation $(\mathrm{CV})$ of pollutant means across the various types.

with a rapid increase in the near-surface $\mathrm{SO}_{2}$ concentration, resulting in a pre-noon peak. Since there is no significant increase in $\mathrm{SO}_{2}$ emission at the surface at that time, the result strongly suggests that the $\mathrm{SO}_{2}$ peaks are due to the downward mixing from the elevated $\mathrm{SO}_{2}$ pollution layers. Regarding the physical mechanism of the noontime-peak $\mathrm{SO}_{2}$ pattern, $\mathrm{Xu}$ et al. (2014) gave a detailed explanation in a previous study. Nevertheless, the wintertime $\mathrm{SO}_{2}$ concentration signature does not always show a distinct pre-noon peak (e.g., Node 7). This may be attributed to the increased $\mathrm{SO}_{2}$ emissions from household heating in winter (Liao et al., 2017). Like other primary pollutants, the local $\mathrm{SO}_{2}$ emissions become trapped close to the surface under stable nocturnal con- ditions, resulting in a much higher nighttime peak compared to the pre-noon peak.

\subsection{Quantifying the contribution of ABL anomaly to typical-month $\mathbf{P M}_{2.5}$ air quality}

To improve air quality, the Chinese government promulgated the "Air Pollution Prevention and Control Action Plan" in 2013. As a consequence, observed annual mean $\mathrm{PM}_{2.5}$ concentrations decreased by about $37 \%$ over Beijing during 2013-2017. However, severe wintertime $\mathrm{PM}_{2.5}$ pollution events still frequently wreak havoc across Beijing and its surroundings, which result in severe damage to the environment and human health (Gao et al., 2017, 2015). It is therefore a 

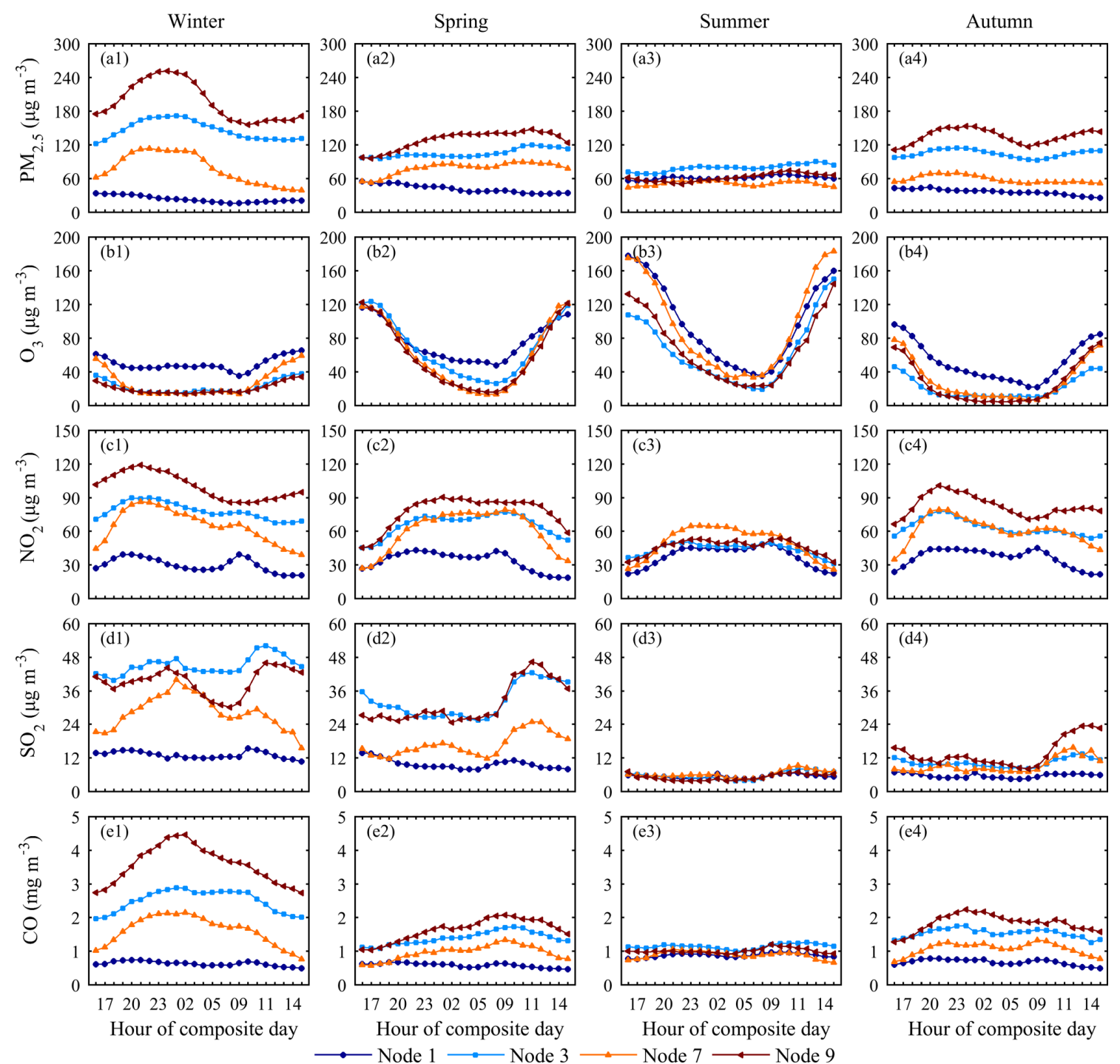

Figure 6. Mean hourly composites of (a) $\mathrm{PM}_{2.5}$, (b) $\mathrm{O}_{3}$, (c) $\mathrm{NO}_{2}$, (d) $\mathrm{SO}_{2}$ and (e) $\mathrm{CO}$ in Beijing for the four typical ABL types separately in (1) winter, (2) spring, (3) summer and (4) autumn.

pressing issue to understand the factors affecting the occurrence of such serious $\mathrm{PM}_{2.5}$ pollution. Previous studies highlighted the potential importance of atmospheric conditions to the wintertime $\mathrm{PM}_{2.5}$ air quality (Cai et al., 2017). Since the fraction of time for which the different atmospheric conditions dominate can vary from year to year, elucidation of the meteorological roles in those serious pollution periods is of significant importance. In this section, we evaluate the contribution of the ABL anomaly to elevated $\mathrm{PM}_{2.5}$ concentration in three typical pollution months, i.e., January 2013, December 2015 and December 2016.

Heavy $\mathrm{PM}_{2.5}$ pollution episodes occurred frequently in January 2013, December 2015 and December 2016, resulting in anomalously high monthly averaged $\mathrm{PM}_{2.5}$ concentrations in the Beijing urban area $\left(180.1,151.8\right.$ and $151.2 \mu \mathrm{g} \mathrm{m}^{-3}$, respectively). Figure 7 shows the hourly $\mathrm{PM}_{2.5}$ variations in the three selected months, along with daily ABL types. In general, the pollution episodes were associated with Nodes 3 and 9 , and the clean episodes corresponded to Node 1. For example, the severe pollution episode that occurred from 9 to 14 January 2013 was due to the alternate control of Nodes 3 and 9, and the pollution episode from 15 to 21 December 2016 was related to the persistency of Node 9. Conversely, multi-day control of Node 1 caused a clean episode from 14 to 16 December 2015. The linkages between $\mathrm{PM}_{2.5}$ air quality and $\mathrm{ABL}$ type are consistent with the previous long-term analyses, indicating that the changing ABL type is one of the primary drivers of day-to-day variations in wintertime $\mathrm{PM}_{2.5}$ air quality over Beijing.

Figure 8 illustrates a comparison of the occurrence frequency of the nine ABL types between the three selected months and the whole 5-year winter period. Compared with 

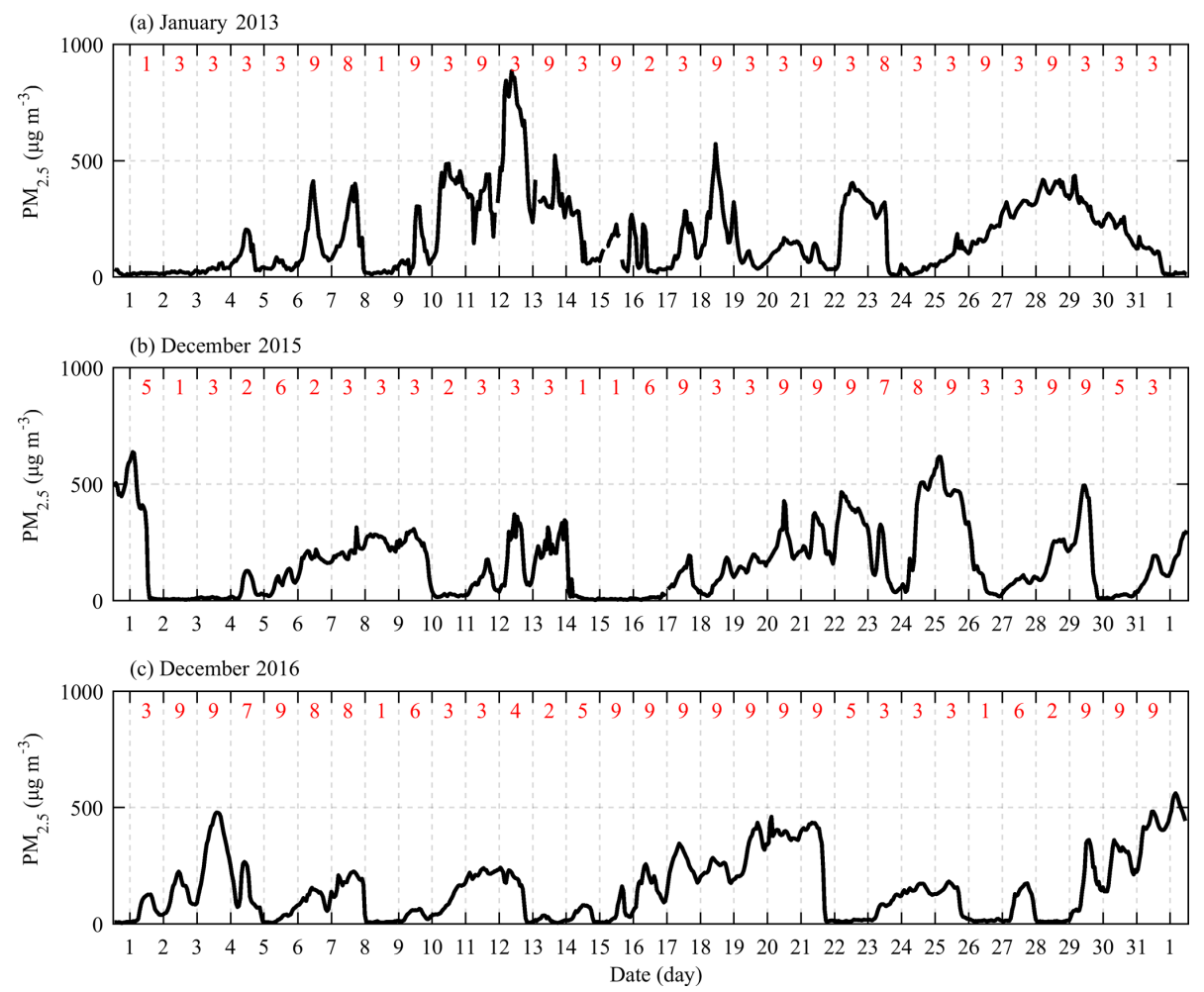

Figure 7. Time series of hourly $\mathrm{PM}_{2.5}$ concentrations in (a) January 2013, (b) December 2015 and (c) December 2016. The daily ABL types (i.e., SOM nodes) are shown at the top of each plot (red numbers).

the winter-averaged frequency, notable differences are that the stable ABL conditions increased and the near neutral nights decreased during the three polluted months. For example, Node 9 occurrence was nearly trebled in December 2016, and total occurrence of Nodes 3 and 9 doubled in January 2013. These results highlight the potential contribution of the ABL anomaly to the elevated $\mathrm{PM}_{2.5}$ concentrations in these pollution months.

Assuming the linkages between ABL type and $\mathrm{PM}_{2.5}$ loading are constant in different years, the contribution of the anomalous $\mathrm{ABL}$ meteorology to $\mathrm{PM}_{2.5}$ air quality can be estimated through a meteorology-environment method, which is a revised version of the circulation-environment method proposed by Zhang et al. (2012). For each selected month, we define the deviation in $\mathrm{PM}_{2.5}$ from the 5-year winteraveraged concentration $\left(C_{\text {WIN }}\right)$ as the total anomaly $\left(C^{\prime}\right)$, which is due to the combined effects of emission and meteorology. The anomaly calculated from the mean $\mathrm{PM}_{2.5}$ loadings for nine $\mathrm{ABL}$ types and their occurrence frequencies during each month can be considered as the "ABL-driven" anomaly, which represents the $\mathrm{PM}_{2.5}$ change caused by the anomalous ABL meteorology. The ABL-driven anomaly $\left(C_{\mathrm{ABL}}\right)$ is calculated through $\sum_{i} F_{i} \cdot C_{i}-C_{\mathrm{WIN}}$, where $F_{i}$ is the occurrence frequency of type $i \mathrm{ABL}$ during a specific month and $C_{i}$ is the corresponding $\mathrm{PM}_{2.5}$ loading featuring that type. The ratio of $C_{\mathrm{ABL}}^{\prime}$ to $C^{\prime}$ is then used to as- sess the relative contribution of the ABL anomaly to the total anomaly. The calculated results (Table 1) show that the ABL-driven $\mathrm{PM}_{2.5}$ changes are $44.4 \mu \mathrm{g} \mathrm{m}^{-3}$ in January 2013 , $22.2 \mu \mathrm{g} \mathrm{m}^{-3}$ in December 2015 and $34.6 \mu \mathrm{g} \mathrm{m}^{-3}$ in December 2016, which explain 58.3, 46.4 and $73.3 \%$ of the total anomaly in respective months. These quantitative estimations demonstrate that the elevated $\mathrm{PM}_{2.5}$ concentrations during the three polluted months can be largely attributed to anomalous ABL conditions.

\section{Summary}

The influence of ABL meteorology on Beijing's air quality is relatively unclear due to the lack of long-term observations. Meanwhile, the long years of routine radiosondes remain underutilized as a tool for urban pollution studies. In this study, the SOM was applied to 5-year (2013-2017) radiosondebased $\theta_{\mathrm{v}}$ profiles to classify the state of the ABL over Beijing. The classified ABL types were then evaluated in relation to near-surface air quality, with an attempt to understand the roles of the changing ABL structure in air quality variation in Beijing. The main findings are as follows.

The SOM provides a continuum of nine ABL types (i.e., SOM nodes), and each is characterized with distinct dynamic and thermodynamic conditions within the ABL. Node 1 represents a near neutral layer, with the lowest $\theta_{v}$ gradient and 

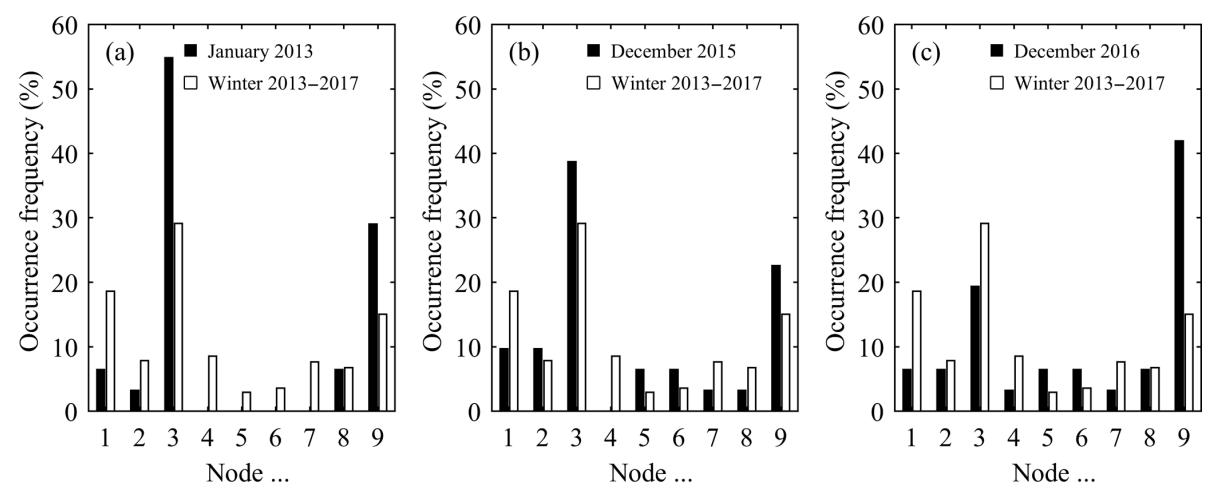

Figure 8. Occurrence frequency of the ABL types (i.e., SOM nodes) during (a) January 2013, (b) December 2015 and (c) December 2016. The winter-averaged frequency during the 5-year (2013-2017) period is repeated on each plot for comparison.

Table 1. Estimated contribution of ABL anomaly to elevated $\mathrm{PM}_{2.5}$ concentration in January 2013, December 2015 and December 2016.

\begin{tabular}{lrrrr}
\hline $\begin{array}{l}\text { Pollution } \\
\text { month }\end{array}$ & $\begin{array}{r}\text { Monthly averaged } \mathrm{PM}_{2.5} \\
\text { concentration }\left(\mu \mathrm{g} \mathrm{m}^{-3}\right)\end{array}$ & $\begin{array}{r}\text { Total anomaly } C^{\prime} \\
\left(\mu \mathrm{g} \mathrm{m}^{-3}\right)\end{array}$ & $\begin{array}{r}\text { ABL-driven anomaly } \\
C_{\mathrm{ABL}}\left(\mu \mathrm{g} \mathrm{m}^{-3}\right)\end{array}$ & $\begin{array}{r}\text { Contribution ratio of } \\
\text { ABL-driven anomaly }(\%)\end{array}$ \\
\hline January 2013 & 180.1 & 76.1 & 44.4 & 58.3 \\
December 2015 & 151.8 & 47.8 & 22.2 & 46.4 \\
December 2016 & 151.2 & 47.2 & 34.6 & 73.3 \\
\hline
\end{tabular}

the highest wind speed. Node 3 features a strong static stability in the upper ABL. In contrast, Node 9 and Node 7 respectively correspond to the moderate and strong static stability in the lower ABL.

The self-organized ABL types are capable of characterizing the influence of nocturnal mixing on near-surface pollutant loadings. From the near neutral (i.e., Node 1) to strong stable conditions (i.e., Node 9), the average concentrations of $\mathrm{PM}_{2.5}, \mathrm{NO}_{2}$ and $\mathrm{CO}$ increased dramatically during all seasons except summer. Meanwhile, the diurnal cycles of these pollutant species are strongly modulated by ABL dynamics. Although the modulation effect varies from season to season, the higher peak concentrations commonly occur under the more stable conditions. However, increasing stability has an opposite effect on $\mathrm{O}_{3}$, resulting in the lowest $\mathrm{O}_{3}$ level in Node 9. For $\mathrm{SO}_{2}$, the highest average concentrations are typically observed in Node 3 . The pre-noon $\mathrm{SO}_{2}$ peaks are more significant after a strong stable night.

Analysis of three typical wintertime pollution months (i.e., January 2013, December 2015 and December 2016) suggests that the ABL types are one of the primary drivers of day-to-day $\mathrm{PM}_{2.5}$ variations in Beijing. During the three pollution months, the frequency of the stable ABL types (i.e., Nodes 9 and 3) increases significantly compared to the 5-year winter mean. Using a meteorology-environment method, the relative (absolute) contributions of the ABL anomaly to elevated $\mathrm{PM}_{2.5}$ concentrations are estimated to be $58.3 \%$ $\left(44.4 \mathrm{~g} \mathrm{~m}^{-3}\right)$ in January $2013,46.4 \%\left(22.2 \mu \mathrm{g} \mathrm{m}^{-3}\right)$ in December 2015 and $73.3 \%\left(34.6 \mu \mathrm{g} \mathrm{m}^{-3}\right)$ in December 2016.
This work revealed the common pattern of the ABL influences on Beijing's air quality. The established linkages between ABL type and air quality could be useful for developing an operational forecast and warning system. In addition, this work demonstrated that the SOM-based ABL classification scheme is a helpful tool for understanding urban air pollution. Since the SOM technique is good at feature extraction, the coarse-resolution radiosondes can be taken as input to classify the state of the ABL. Therefore, the SOM-based ABL classification scheme can take advantage of the longterm available radiosondes, making it a simple and economical alternative to other approaches to stability classification. We believe that the pollution-related ABL research and the formulation of pollution control measures could benefit from application of the SOM analytical tool.

Data availability. The datasets used in this study are publicly available at the University of Wyoming (http://weather.uwyo.edu/), the Ministry of Environmental Protection of the People's Republic of China (http://datacenter.mep.gov.cn/) and the US Department of State Air Quality Monitoring Program (http://www.stateair.net/).

Competing interests. The authors declare that they have no conflict of interest.

Acknowledgements. This study is supported by the National Key Research and Development Plan of China (no. 2017YFC0209606 and 2016YFC0203305), the National Natural Science Foundation 
of China (no. 41630422, 41475140 and 41475004) and the Special Fund for Basic Scientific Research Business of Central Public Research Institutes (PM-zx703-201601-019). The authors would like to thank the Beijing Meteorological Bureau, the Ministry of Environmental Protection of the People's Republic of China and the Wyoming Weather Web for providing relevant data.

Edited by: Heini Wernli

Reviewed by: two anonymous referees

\section{References}

Cai, W. J., Li, K., Liao, H., Wang, H. J., and Wu, L. X.: Weather conditions conducive to Beijing severe haze more frequent under climate change, Nat. Clim. Change, 7, 257-262, https://doi.org/10.1038/Nclimate3249, 2017.

Chambers, S. D., Wang, F. J., Williams, A. G., Deng, X. D., Zhang, H., Lonati, G., Crawford, J., Griffiths, A. D., Ianniello, A., and Allegrini, I.: Quantifying the influences of atmospheric stability on air pollution in Lanzhou, China, using a radon-based stability monitor, Atmos. Environ., 107, 233-243, https://doi.org/10.1016/j.atmosenv.2015.02.016, 2015a.

Chambers, S. D., Williams, A. G., Crawford, J., and Griffiths, A. D.: On the use of radon for quantifying the effects of atmospheric stability on urban emissions, Atmos. Chem. Phys., 15, 1175-1190, https://doi.org/10.5194/acp-15-1175-2015, 2015 b.

Chen, L.-W. A., Watson, J. G., Chow, J. C., Green, M. C., Inouye, D., and Dick, K.: Wintertime particulate pollution episodes in an urban valley of the Western US: a case study, Atmos. Chem. Phys., 12, 10051-10064, https://doi.org/10.5194/acp-12-100512012, 2012.

Chen, Y., Zhao, C. S., Zhang, Q., Deng, Z. Z., Huang, M. Y., and Ma, X. C.: Aircraft study of Mountain Chimney Effect of Beijing, China, J. Geophys. Res.-Atmos, 114, D08306, https://doi.org/10.1029/2008jd010610, 2009.

Chen, Z. H., Cheng, S. Y., Li, J. B., Guo, X. R., Wang, W. H., and Chen, D. S.: Relationship between atmospheric pollution processes and synoptic pressure patterns in northern China, Atmos. Environ., 42, 6078-6087, https://doi.org/10.1016/j.atmosenv.2008.03.043, 2008.

Dyson, L. L.: A heavy rainfall sounding climatology over Gauteng, South Africa, using self-organising maps, Clim. Dynam., 45, 3051-3065, https://doi.org/10.1007/s00382-015-2523-3, 2015.

Fan, S. J., Wang, B. M., Tesche, M., Engelmann, R., Althausen, A., Liu, J., Zhu, W., Fan, Q., Li, M. H., Ta, N., Song, L. L., and Leong, K. C.: Meteorological conditions and structures of atmospheric boundary layer in October 2004 over Pearl River Delta area, Atmos. Environ., 42, 6174-6186, https://doi.org/10.1016/j.atmosenv.2008.01.067, 2008.

Gao, M., Guttikunda, S. K., Carmichael, G. R., Wang, Y. S., Liu, Z. R., Stanier, C. O., Saide, P. E., and Yu, M.: Health impacts and economic losses assessment of the 2013 severe haze event in Beijing area, Sci. Tot. Environ., 511, 553-561, https://doi.org/10.1016/j.scitotenv.2015.01.005, 2015.

Gao, M., Carmichael, G. R., Wang, Y., Saide, P. E., Yu, M., Xin, J., Liu, Z., and Wang, Z.: Modeling study of the 2010 regional haze event in the North China Plain, Atmos. Chem. Phys., 16, 1673-1691, https://doi.org/10.5194/acp-16-1673-2016, 2016.
Gao, M., Saide, P. E., Xin, J. Y., Wang, Y. S., Liu, Z. R., Wang, Y. X., Wang, Z. F., Pagowski, M., Guttikunda, S. K., and Carmichael, G. R.: Estimates of Health Impacts and Radiative Forcing in Winter Haze in Eastern China through Constraints of Surface $\mathrm{PM}_{2.5}$ Predictions, Environ. Sci. Tech., 51, 2178-2185, https://doi.org/10.1021/acs.est.6b03745, 2017.

Gibson, P. B., Perkins-Kirkpatrick, S. E., and Renwick, J. A.: Projected changes in synoptic weather patterns over New Zealand examined through self-organizing maps, Int. J. Climatol., 36, 3934-3948, https://doi.org/10.1002/joc.4604, 2016.

Guinot, B., Roger, J. C., Cachier, H., Wang, P. C., Bai, J. H., and Tong, Y.: Impact of vertical atmospheric structure on Beijing aerosol distribution, Atmos. Environ., 40, 5167-5180, https://doi.org/10.1016/j.atmosenv.2006.03.051, 2006.

Guo, J., Miao, Y., Zhang, Y., Liu, H., Li, Z., Zhang, W., He, J., Lou, M., Yan, Y., Bian, L., and Zhai, P.: The climatology of planetary boundary layer height in China derived from radiosonde and reanalysis data, Atmos. Chem. Phys., 16, 13309-13319, https://doi.org/10.5194/acp-16-13309-2016, 2016.

Guo, X. F., Yang, T., Miao, S. G., and Sun, Y. L.: Urban BoundaryLayer Stability and Turbulent Exchange during Consecutive Episodes of Particle Air Pollution in Beijing, China, Atmos. Ocean. Sci. Lett., 7, 62-66, https://doi.org/10.3878/j.issn.16742834.13.0067, 2014.

Holzworth, G. C.: Estimates of mean maximun mixing depths in the contiguous United States, Mon. Weather Rev., 92, 235-242, 1964.

Holzworth, G. C.: Mixing depths, wind speeds and air pollution potential for selected locations in the United States, J. Appl. Meteorol., 6, 1039-1044, 1967.

Hu, X. M., Ma, Z. Q., Lin, W. L., Zhang, H. L., Hu, J. L., Wang, Y., Xu, X. B., Fuentes, J. D., and Xue, M.: Impact of the Loess Plateau on the atmospheric boundary layer structure and air quality in the North China Plain: A case study, Sci. Tot. Environ., 499 228-237, https://doi.org/10.1016/j.scitotenv.2014.08.053, 2014.

Hua, Y., Wang, S., Wang, J., Jiang, J., Zhang, T., Song, Y., Kang, L., Zhou, W., Cai, R., Wu, D., Fan, S., Wang, T., Tang, X., Wei, Q., Sun, F., and Xiao, Z.: Investigating the impact of regional transport on $\mathrm{PM}_{2.5}$ formation using vertical observation during APEC 2014 Summit in Beijing, Atmos. Chem. Phys., 16, 1545115460, https://doi.org/10.5194/acp-16-15451-2016, 2016.

Jensen, A. A., Thompson, A. M., and Schmidlin, F. J.: Classification of Ascension Island and Natal ozonesondes using self-organizing maps, J. Geophys. Res.-Atmos, 117, D04302, https://doi.org/10.1029/2011jd016573, 2012.

Ji, D. S., Wang, Y. S., Wang, L. L., Chen, L. F., Hu, B., Tang, G. Q., Xin, J. Y., Song, T., Wen, T. X., Sun, Y., Pan, Y. P., and Liu, Z. R.: Analysis of heavy pollution episodes in selected cities of northern China, Atmos. Environ., 50, 338-348, https://doi.org/10.1016/j.atmosenv.2011.11.053, 2012.

Jiang, N. B., Scorgie, Y., Hart, M., Riley, M. L., Crawford, J., Beggs, P. J., Edwards, G. C., Chang, L. S., Salter, D., and Virgilio, G. D.: Visualising the relationships between synoptic circulation type and air quality in Sydney, a subtropical coastal-basin environment, Int. J. Climatol., 37, 1211-1228, https://doi.org/10.1002/joc.4770, 2017.

Katurji, M., Noonan, B., Zawar-Reza, P., Schulmann, T., and Sturman, A.: Characteristics of the Springtime Alpine Valley Atmospheric Boundary Layer Using Self-Organizing Maps, J. Appl. 
Meteorol. Clim., 54, 2077-2085, https://doi.org/10.1175/JamcD-14-0317.1, 2015.

Kaufman, Y. J., Tanre, D., and Boucher, O.: A satellite view of aerosols in the climate system, Nature, 419, 215-223, https://doi.org/10.1038/nature01091, 2002.

Kohonen, T.: Self-organized information of topologically correct features maps, Biol. Cyb., 43, 59-69, 1982.

Kohonen, T.: Self-organizing maps, 3rd edn. Springer, London, 2001.

Lennard, C. and Hegerl, G.: Relating changes in synoptic circulation to the surface rainfall response using self-organising maps, Clim. Dynam., 44, 861-879, https://doi.org/10.1007/s00382014-2169-6, 2015.

Li, Y. Y., Yan, J. P., and Sui, X. B.: Tropospheric temperature inversion over central China, Atmos. Res., 116, 105-115, https://doi.org/10.1016/j.atmosres.2012.03.009, 2012.

Liao, J. W., Jin, A. Z., Chafe, Z. A., Pillarisetti, A., Yu, T., Shan, M., Yang, X. D., Li, H. X., Liu, G. Q., and Smith, K. R.: The impact of household cooking and heating with solid fuels on ambient $\mathrm{PM}_{2.5}$ in peri-urban Beijing, Atmos. Environ., 165, 62-72, https://doi.org/10.1016/j.atmosenv.2017.05.053, 2017.

Liu, H. Z., Feng, J. W., Järvi, L., and Vesala, T.: Four-year (20062009) eddy covariance measurements of $\mathrm{CO}_{2}$ flux over an urban area in Beijing, Atmos. Chem. Phys., 12, 7881-7892, https://doi.org/10.5194/acp-12-7881-2012, 2012.

Liu, Y. G., Weisberg, R. H., and Mooers, C. N. K.: Performance evaluation of the self-organizing map for feature extraction, J. Geophys Res.-Ocean, 111, C05018, https://doi.org/10.1029/2005jc003117, 2006.

Miao, Y., Guo, J., Liu, S., Liu, H., Li, Z., Zhang, W., and Zhai, P.: Classification of summertime synoptic patterns in Beijing and their associations with boundary layer structure affecting aerosol pollution, Atmos. Chem. Phys., 17, 3097-3110, https://doi.org/10.5194/acp-17-3097-2017, 2017.

Pearce, J. L., Waller, L. A., Chang, H. H., Klein, M., Mulholland, J. A., Sarnat, J. A., Sarnat, S. E., Strickland, M. J., and Tolbert, P. E.: Using self-organizing maps to develop ambient air quality classifications: a time series example, Environ. Health-Glob., 13, https://doi.org/10.1186/1476-069X-13-56, 2014.

Platis, A., Altstadter, B., Wehner, B., Wildmann, N., Lampert, A., Hermann, M., Birmili, W., and Bange, J.: An Observational Case Study on the Influence of Atmospheric Boundary-Layer Dynamics on New Particle Formation, Bound.-Lay. Meteor., 158, 67-92, https://doi.org/10.1007/s10546-015-0084-y, 2016.

Quan, J. N., Gao, Y., Zhang, Q., Tie, X. X., Cao, J. J., Han, S. Q., Meng, J. W., Chen, P. F., and Zhao, D. L.: Evolution of planetary boundary layer under different weather conditions, and its impact on aerosol concentrations, Particuology, 11, 34-40, https://doi.org/10.1016/j.partic.2012.04.005, 2013.

Salmond, J. A. and McKendry, I. G.: A review of turbulence in the very stable nocturnal boundary layer and its implications for air quality, Prog. Phys. Geo., 29, 171-188, https://doi.org/10.1191/0309133305pp442ra, 2005.

Stauffer, R. M., Thompson, A. M., and Young, G. S.: Tropospheric ozonesonde profiles at long-term US monitoring sites: 1. A climatology based on self-organizing maps, J. Geophys. Res.-Atmos, 121, 1320-1339, https://doi.org/10.1002/2015JD023641, 2016.
Stull, R. B.: An Introduction to Boundary Layer Meteorology, Kluwer Academic Publishers, 1988.

Sun, Y., Song, T., Tang, G. Q., and Wang, Y. S.: The vertical distribution of $\mathrm{PM}_{2.5}$ and boundary-layer structure during summer haze in Beijing, Atmos. Environ., 74, 413-421, https://doi.org/10.1016/j.atmosenv.2013.03.011, 2013.

Sun, Y. L., Du, W., Wan, Q. Q., Zhang, Q., Chen, C., Chen, Y., Chen, Z. Y., Fu, P. Q., Wang, Z. F., Gao, Z. Q., and Worsnop, D. R.: Real-Time Characterization of Aerosol Particle Composition above the Urban Canopy in Beijing: Insights into the Interactions between the Atmospheric Boundary Layer and Aerosol Chemistry, Environ. Sci. Tech., 49, 11340-11347, https://doi.org/10.1021/acs.est.5b02373, 2015.

Tang, G., Zhu, X., Hu, B., Xin, J., Wang, L., Münkel, C., Mao, G., and Wang, Y.: Impact of emission controls on air quality in Beijing during APEC 2014: lidar ceilometer observations, Atmos. Chem. Phys., 15, 12667-12680, https://doi.org/10.5194/acp-1512667-2015, 2015.

Tang, G., Zhang, J., Zhu, X., Song, T., Münkel, C., Hu, B., Schäfer, K., Liu, Z., Zhang, J., Wang, L., Xin, J., Suppan, P., and Wang, Y.: Mixing layer height and its implications for air pollution over Beijing, China, Atmos. Chem. Phys., 16, 2459-2475, https://doi.org/10.5194/acp-16-2459-2016, 2016.

Tang, G. Q., Zhu, X. W., Xin, J. Y., Hu, B., Song, T., Sun, Y., Wang, L. L., Wu, F. K., Sun, J., Cheng, M. T., Chao, N., Li, X., and Wang, Y. S.: Modelling study of boundary-layer ozone over northern China - Part II: Responses to emission reductions during the Beijing Olympics, Atmos. Res., 193, 83-93, https://doi.org/10.1016/j.atmosres.2017.02.014, 2017a.

Tang, G. Q., Zhu, X. W., Xin, J. Y., Hu, B., Song, T., Sun, Y., Zhang, J. Q., Wang, L. L., Cheng, M. T., Chao, N., Kong, L. B., Li, X., and Wang, Y. S.: Modelling study of boundary-layer ozone over northern China - Part I: Ozone budget in summer, Atmos. Res., 187, 128-137, https://doi.org/10.1016/j.atmosres.2016.10.017, 2017b.

Whiteman, C. D., Hoch, S. W., Horel, J. D., and Charland, A.: Relationship between particulate air pollution and meteorological variables in Utah's Salt Lake Valley, Atmos. Environ., 94, 742753, https://doi.org/10.1016/j.atmosenv.2014.06.012, 2014.

Wolf, T., Esau, I., and Reuder, J.: Analysis of the vertical temperature structure in the Bergen valley, Norway, and its connection to pollution episodes, J. Geophys. Res.-Atmos, 119, 10645-10662, https://doi.org/10.1002/2014JD022085, 2014.

Wu, M., Wu, D., Fan, Q., Wang, B. M., Li, H. W., and Fan, S. J.: Observational studies of the meteorological characteristics associated with poor air quality over the Pearl River Delta in China, Atmos. Chem. Phys., 13, 10755-10766, https://doi.org/10.5194/acp-13-10755-2013, 2013.

Xu, W. Y., Zhao, C. S., Ran, L., Lin, W. L., Yan, P., and Xu, X. B.: $\mathrm{SO}_{2}$ noontime-peak phenomenon in the North China Plain, Atmos. Chem. Phys., 14, 7757-7768, https://doi.org/10.5194/acp14-7757-2014, 2014.

Xu, X., Zhao, T., Liu, F., Gong, S. L., Kristovich, D., Lu, C., Guo, Y., Cheng, X., Wang, Y., and Ding, G.: Climate modulation of the Tibetan Plateau on haze in China, Atmos. Chem. Phys., 16, 1365-1375, https://doi.org/10.5194/acp-16-1365-2016, 2016.

Ye, X. X., Song, Y., Cai, X. H., and Zhang, H. S.: Study on the synoptic flow patterns and boundary layer process of the severe haze events over the North China 
Plain in January 2013, Atmos. Environ., 124, 129-145, https://doi.org/10.1016/j.atmosenv.2015.06.011, 2016.

Zhang, J. K., Sun, Y., Liu, Z. R., Ji, D. S., Hu, B., Liu, Q., and Wang, Y. S.: Characterization of submicron aerosols during a month of serious pollution in Beijing, 2013, Atmos. Chem. Phys., 14, 2887-2903, https://doi.org/10.5194/acp-14-2887-2014, 2014.

Zhang, J. P., Zhu, T., Zhang, Q. H., Li, C. C., Shu, H. L., Ying, Y., Dai, Z. P., Wang, X., Liu, X. Y., Liang, A. M., Shen, H. X., and Yi, B. Q.: The impact of circulation patterns on regional transport pathways and air quality over Beijing and its surroundings, Atmos. Chem. Phys., 12, 5031-5053, https://doi.org/10.5194/acp12-5031-2012, 2012.

Zhang, Q., Ma, X. C., Tie, X. X., Huang, M. Y., and Zhao, C. S.: Vertical distributions of aerosols under different weather conditions: Analysis of in-situ aircraft measurements in Beijing, China, Atmos. Environ., 43, 5526-5535, https://doi.org/10.1016/j.atmosenv.2009.05.037, 2009.
Zhao, B., Wang, P., Ma, J. Z., Zhu, S., Pozzer, A., and Li, W.: A high-resolution emission inventory of primary pollutants for the Huabei region, China, Atmos. Chem. Phys., 12, 481-501, https://doi.org/10.5194/acp-12-481-2012, 2012.

Zhao, X. J., Zhao, P. S., Xu, J., Meng, W., Pu, W. W., Dong, F., He, D., and Shi, Q. F.: Analysis of a winter regional haze event and its formation mechanism in the North China Plain, Atmos. Chem. Phys., 13, 5685-5696, https://doi.org/10.5194/acp13-5685-2013, 2013.

Zhu, X. W., Tang, G. Q., Hu, B., Wang, L. L., Xin, J. Y., Zhang, J. K., Liu, Z. R., Munkel, C., and Wang, Y. S.: Regional pollution and its formation mechanism over North China Plain: A case study with ceilometer observations and model simulations, J. Geophys. Res.-Atmos, 121, 14574-14588, https://doi.org/10.1002/2016JD025730, 2016. 